\title{
Innovative Hr Practices for Emerging and Small Business Organisation in the Modern World
}

\author{
Soumya K \\ Faculty in commerce MES ponnani college ponnani, Kerala india
}

\begin{abstract}
While much of our knowledge concerning traditional HR topics (e.g., recruiting, compensation, or performance management) in large firms may also apply in small or emerging organizations, evidence suggests that new ventures are different and that management of people within them may not clearly map to management within larger, more established organizations. This paper reviews extant research on managing people within small and emerging ventures and highlights additional questions that have not yet been addressed. Management could benefit from looking more closely at HR processes within new and small firms. . This paper reviews what we know about HRM in entrepreneurial organizations in order to highlight important gaps in this understanding. An emerging area of study has focused on the role of the founder in new venture creation, specifically on the characteristics of those individuals, such as leadership self-efficacy, perseverance, risktaking ability, and role transitions they experience during venture emergence.
\end{abstract}

Keywords: Entrepreneurship, Human resource management, Leadership, New ventures, Small firms

\section{Introduction}

Employees are very important components or assets of an organization and this is the main reason why an organization must do human resource management. They need to be managed successfully needless of the size of the organization because the employees contribute to the delivery of products and services. Even an organisation having two to three employees can face challenging resource management issues. An employee's abilities, loyalty and commitment can be boosted through effective HR management. Every business enterprise need loyal, efficient and hard working employee. Most small business employers have no formal training in how to make hiring decisions, noted Jill A. Rossiter in Human Resources: Mastering Your Small Business. Most have no real sense of the time it takes nor the costs involved. All they know is that they need help in the form of a 'good' sales manager, a good secretary, a 'good' welder, or whatever. And they know they need some-one they can work with, who's willing to put in the time to learn the business and do the job. It sounds simple, but it isn't Small and new enterprises need to document the policies and procedures followed for managing human resources. The owner can take help of the employees for making a rule book or the personnel manual to ensure that the owner and the employees are on the same page.

\section{Objectives Of Te Study}

- TO study hr practices in the modern world regarding small and emerging organisations

- To study the effectiveness $\mathrm{hr}$ in the modern business organisation.

\section{Research Methodology}

This study uses data from secondary data sources such as books, journals, Newspapers and online database

\section{Functions Of Hrm In Small Organisations}

Human Resource Department or Human Resource Manager of an organisation has to perform certain functions to justify their presence in an organisation. These functions are more or less same for most organisations irrespective of their size HR managers in small organisations have to perform following functions on regular basis

\subsection{Adherence to rules \& regulations}

It is important for the Hr department in all the organizations to follow the rules and regulations which have impact on human resources from hiring them through their termination, which includes their safety, benefits, etc. even very small companies having one to fourteen employees should also comply with fair labour standards, equal pay, etc.

\subsection{Benefit Administration}

Administration is involved in all sizes \& types of companies. HR management can help the small organizations by doing the research to find out which benefits can be most cost-effective for the organization 
and how the provisions of these benefits will be managed which will need a lot of administrative work. HR can also benefit a company by being in tune with the employees and getting to know what benefits employees value most.

\subsection{Various hiring practices}

HRM department provides effective hiring practices to an organization. A good hire is one where the required skills, abilities and know-how required by a job matches the person hired for the job and the culture of the small organization

\subsection{Training \& Development}

Since small firms have less number of people working with them so it is more important for them to provide cross training to the employees to cover more than one job function or task. HR management can provide the small organizations with effective and low cost training techniques.

\subsection{Employee Recognition}

Small enterprises have limited number of employees and low budgets for employee benefits so the HR management can help in terms of employee recognition programs that value employees and keep them committed to the organization. Employees can also give their views during such programs and when their ideas are implemented then it acts as a morale booster which in turn reduces employee turnover.

\subsection{Global Human Resources}

Small businesses are also tapping global markets these days. It is the responsibility of HR manager to develop capable staff with cultural fluency for initiating and sustaining overseas relationships. Small enterprises have limited resources so the HR manager has to keep this in mind while hiring suitable employee for placement in foreign office.

\subsection{Multigenerational Diversity}

HR manager has to deal with multiple generations in one organisation. One generation may be tech savvy while the other may prefer face to face interaction. In small and emerging enterprises, due to lack of resources and know how, the manager has to find a way to bridge the gap between these various generations.

\section{Key Challenges Of HR In Small And Emerging Org:}

Paying attention to HR in small businesses and start-ups is not that common which is why HR managers face certain key challenges in trying to make entrepreneurs see how Human Resource Management can help take their business to new heights.

According to a study conducted by The Society for Human Resource Management (SHRM), here are some of the challenges that HR managers are most likely to face within a span of 10 years.

- Almost 59\% feel that retaining and rewarding top employees is a major issue

- While $52 \%$ think that developing the next generation of leaders is a tough challenge

- Lastly, 36\% feel that creating a work-friendly culture attracts the best and the most talented employees

In order to retain top talent and reward them generously, it is important to provide employees with work flexibility. Gone are the days when work from home days used to be the goof off days. You can now carefully monitor the performance of employees, or at least offer flexible office hours, to facilitate top talent and satisfy both the employees and the employer.

Small business organisation has the opportunity to create a work-friendly, easygoing environment with an open culture so the employees can relax and focus on work. HR managers working in such small-scale companies can easily resolve work-place problems by having one-on-one interactions with the employees and share valuable information.

Every employee wants to go far in their professional career and a company with few top positions cannot offer as many promotions and rewards as a big corporation would. In such a situation, HR managers can move employees laterally to enrich the work experience by offering them the chance to learn new skills, job share or cross train. You can also throw in some extra perks like providing top talent a chance to visit industry conferences or other events to add value.

No doubt, SMEs and start-ups cannot compete with bigger corporations when it comes to offering glamorous salary packages and benefits. Make sure you offer a competitive salary and offer as many benefits to your team as possible, such as health insurance, life insurance, retirement plans, etc. In order to sweeten the deal even more, offer soft benefits like flexible hours and performance-based benefits like profit sharing. 


\section{Key Objectives Of HR In SMES And Start-Ups}

HRM for small businesses and start-ups is different from that of big corporations because the professionals strive to establish effective performance management in order to identify development opportunities, reward excellence, and provide disciplinary or remedial actions when necessary.

To achieve the maximum level of profitability and success, an HR professional will align each employee's work with the strategic goals of the firm and also ensure that the staffs is well aware of the required actions and behaviours by setting clear-cut performance expectations in job descriptions. Take a look at some of the key HR objectives that apply to SMEs and start-ups:

\subsection{Develop a Competency Model}

The main objective of an HR department is to jobs keeping in minded their skills, expertise, and education. This objective is achieved by setting clear job descriptions, establishing job competency models for each department in the company and benchmarking roles against similar jobs in the industry.

In order to ensure smooth running of the business, HR professionals will take into account studies and data related to staffing, transactions, and costs and then create a competency model accordingly.

\subsection{Define Organizational Dimensions}

HR strategies are developed according to the aspects of the organization. It is also interesting to note that the prevailing culture of the company not only has a critical impact on the HR strategies devised but also represents the management style and values of the organization. Defining the organizational dimensions will give you an idea on how the organization is going to be more or less - will it be an organization that expects employees to 'do more with less' or will it be overstaffed in order to give way to innovation and experimentation?

Some other key factors that directly impact the HR strategies devised are the nature of business done by the organization, the chain of command and the structure of the organization itself. In order to effectively hire and retain staff to achieve strategic goals of the organization, human resources systems, policies, and practices are also taken into account.

\subsection{Define Role of Mission, Vision, and Values}

The mission, vision and values of the small business or start-up play a crucial role in shaping the HR strategies and objectives for the future ahead. The mission of the organization will help you understand why the business exists and who it serves while the vision statement basically provides insights on what the organization hopes to achieve and where it sees itself in the future.

The values of the organization are beliefs that serve as a driving force behind the operations and actions of the organization. All three - the mission, vision and values of the organization directly impact the type and number of employees needed to meet the organizational goals.

\subsection{Perform Workforce Analysis}

A workforce analysis is considered a key part of the human resource strategy and focuses mainly on the organization, its culture, people, and the systems that have been implemented. Doing a workforce analysis is helpful in analyzing the current situation of the company in terms of the elements discussed above and where they ideally want to be in the years to come.

Identifying the gaps in these areas will enable the HR professionals to come up with specific objectives designed especially to bridge these gaps.

\subsection{Evaluate Implemented Strategy}

All HR strategies are guided by evaluation based on specific, measurable factors. A small business or start-up will consider a wide variety of factors for developing, implementing and evaluating the effectiveness and performance of its HR strategy. Usually, doing an evaluation will give you accurate facts and figures on employee turnover, number of vacant positions, customer complaints, and employee grievances along with the satisfaction and dissatisfaction levels of both customers and employees.

\section{Findings}

- creating a work-friendly culture attracts the best and the most talented employees

- In order to retain top talent it is important to provide employees with work flexibility

- Offer a competitive salary and offer as many benefits to employees as possible, such as health insurance, life insurance, retirement plans, etc. 


\section{Conclusion}

It's found that growing importance of small enterprises has become a global trend which has derived productivity, innovation and employment growth in both developed and developing nations. But their increased importance has failed to reduce the challenges and obstacles being faced by them. 30 to 50 percent of the small and new enterprises fail every year. There are many reasons for this failure such as lack of planning and organization, lack of knowledge or experience, lack of both financial and human resources, etc. Human resource management in small enterprises is still in exploratory stage and they use less sophisticated HRM practices which may be because of lack of funds. The owners also have a great impact on the HR policies followed by the companies and HR managers lack in their action under this influence. Small firms provide lower wages to the employees as compared with their large counterparts and they also tend to provide less training facilities to their employees. But they have a behavioural advantage in managing employee relationships due to lack of formal or professional policy towards employee management. HRM patterns come in two different forms in Small organizations which are (a) written procedures, documents, roles and instructions, and (b) informal procedures or ways of doing things. The patterns can establish in any of the community members mind and they become routine and others start following it. Small and emerging enterprises should document policies regarding human resources issues and they need to consider the training and development needs for their employees. They should spend on training only if required. The owner should maintain a productive atmosphere to make the employees contribute more toward achieving the common business objective.

\section{References}

[1]. Bae, JJ Lawler - Academy of management journal

[2]. B Schneider - Personnel psychology, 2008 - Wiley Online Library J Gould-Williams - International journal of human resource 